\title{
Development of Economic Models for EOL Service Parts Control
}

\author{
Wan Seon Shin ${ }^{1}$, Han Sang Lee ${ }^{2}$, Heungsoon Felix Lee ${ }^{3}$ \\ ${ }^{1}$ System Management Engineering, Sungkyunkwan University, Suwon, South Korea; ${ }^{2}$ Energy Solution, LG Chem, Ochang, South \\ Korea; ${ }^{3}$ Industrial \& Manufacturing Engineering, Southern Illinois University Edwardsville, Illinois, USA. \\ Email: wsshin@skku.ac.kr,orgmtoom@naver.com,hflee@siue.edu
}

Received May $30^{\text {th }}, 2012$; revised June $29^{\text {th }}, 2012$; accepted July $27^{\text {th }}, 2012$

\begin{abstract}
This paper deals with a decision problem for final purchase quantity needed for the appropriate support of service parts for S Electronics which is one of the largest electronics companies in the world. The cost elements of the final purchase quantity, the economic models, the optimal solution methods, and the expected effect are presented.
\end{abstract}

Keywords: Spare Parts; Final Purchase; Economic Model

\section{Introduction}

$\mathrm{S}$ Electronics has business around the world. Procurement of service parts about a variety of products for sale is an important competitive factor [1]. The company views the effective order management of electronic products after services as the key factor to customer satisfaction and cost saving. Annual service parts inventory procurement costs over $\$ 100$ million domestically alone. It is therefore clear that controlling service part inventories is of great importance in reducing costs and enhancing service competitiveness.

[2] divides the service part life cycle into three different phases: Initial, normal, and final phases.

1) The initial phase: New components and sub-assemblies are being introduced. Very little is known about their failure behavior and demand [3].

2) The normal phase: Some experiences have been gained for parts in use longer than the initial phase. Often times, a demand forecast model is used for production planning.

3) The final phase: Production of the product has stopped, but the service period however continues. Service managers often place a final production order at the beginning of this phase to deal with the on-going services [4,5].

One important issue in service parts supply for S Electronics is to determine the order quantity of service parts in the final phase (which we call the end of life phase, EOL phase), which is the focus of this paper. [5] term this as the final order. In this paper, we call it "Lastbuy" (denote as LTB) according to the actual field terminology at $\mathrm{S}$ Electronics.
Apparently, the control of service parts is a complex matter. Common statistical models for inventory control lose their applicability, because the demand process is different from those assumed. An essential element in many models such as forecasting demand requires some historical demand figures which are unavailable or invalid for slow moving parts. Moreover, the shorter life cycles of products and better product quality further reduce the possibility of collecting historical demand figures for service parts. In this paper, we present economic models more reflected by characteristics of parts and management's polices and knowledge from statistical models.

This study addresses a method that determines the economic Lastbuy quantity. There are three specific research topics. The first topic is to identify the cost elements related to the last buy and develop the economic model. The second topic is to develop a solution method to determine the optimal Lastbuy quantity. The last topic is to analyze the effects of the proposed economic model and the optimal Lastbuy quantity.

\section{Literature Review}

In the service area, service parts management is one of the most important topics. Its main element is the control of the inventories of service parts. All over the world billions of dollars have been invested in these inventories. Due to the uncertainty in demand both in time and location, however, there can be stock-outs causing many emergency transports and even production losses. On the other hand, stocks regularly need to be discarded: Typi- 
cal obsolescence rates are in the order of $10 \%$. Most logistic theories developed so far apply to the forward chain only and are not relevant for the aftermarket. Service parts inventory differs from finished inventories, because demand is not predicable, often erratic and quite often lumpy (long periods without demand followed with short periods of high demand). Moreover, service parts can be much more critical than finished goods. Hence better decision support is needed for service parts management [6].

In this paper, we address a problem to determine an optimal final order to save the cost of EOL (end of life) services. When inventory control in the literature is limited to procurement (manufacturing inventories are excluded), [7] divides the decision approaches to procurement into two groups: Mathematical modeling and classification. The first one entails cost minimization or modeling based on statistical distributions or failure rates, while the second one does different ways to classify spare parts to homogeneous classes, having an individual procurement strategy for each of them. [7] notes that classification is also important when using mathematical models in purchasing decisions or control parameter choice, so the two are not mutually exclusive.

Among the mathematical models, the cost minimizing approach to procurement is more common. [8] contains well-known cost minimizing strategies that produce ordering quantities and order time-points as output. The most popular ones are Economic Order Quantities, Periodic Order Quantities, Part Period Balancing or McLaren's Order Moment. Although theoretically elaborate, they depend heavily on demand forecast and on-going reordering strategies, which are not applicable to the final phase of a service part. [9] study the problem of determining the optimal service inventory level for a multi-echelon repairable-item inventory system which has several bases with a central depot. When an item fails, it is dispatched to a repair facility and a service, if available, is plugged in immediately. An optimal algorithm is developed to find the spares level that minimizes the total expected cost and simultaneously satisfies a specified service rate.

These research works differ from the work of this paper in that they do not incorporate the cost effects posterior to the EOL service of the product. The proposed research in this paper is unique in two aspects. First, it proposes the theoretical framework and solution method for the Lastbuy model in determining the optimal order quantity based on the economic criterion. Second, the proposed method is then applied to an on-going real world problem of S Electronics.

\section{Two Lastbuy Economic Models}

Cost factors of the proposed Lastbuy economic models (Figure 1) are classified as order cost, inventory cost, shortage cost, and good-will cost. These cost factors should be considered until the guarantee of the supply period. Table 1 shows the notations and symbols of cost terms. Each cost term is determined by a variety of factors. For example, the inventory cost per unit is affected by the size of product while the shortage cost per unit is affected by the good-will cost.

Table 1. Cost factors of the economic models.

\begin{tabular}{llc}
\hline Cost Factors & Descriptions & Cost Notations \\
\hline ORDERING COST & Price of one unit of the part in order & $c l$ \\
RE-ORDERING COST & $\begin{array}{l}\text { Price of one unit of the re-order part } \\
\text { Cost of holding one part of the part in stock including capital, warehousing, } \\
\text { depreciation, insurance, taxation, obsolescence, and shrinkage costs. } \\
\text { INVENTORY COST }\end{array}$ & $c r$ \\
SHORTAGE COST & $\begin{array}{l}\text { Loss of profit per unit of the part from lost sales, and loss of future profit due to loss of goodwill } \\
\text { FIXED RE-ORDER COST }\end{array}$ & $\begin{array}{l}\text { Fixed cost associated with a re-order of the part including the setup cost for a } \\
\text { production line to produce a batch of parts discontinued }\end{array}$ \\
\hline
\end{tabular}



Figure 1. Description of the Lastbuy economic model. 
Definitions of the economic model terms are given in Table 2 Part demand quantity during period $t$ is based on part reliability and a number of parts currently being in use by customers. We assume that this part demand $D(t)$ at $t$ follows a Poisson distribution with mean $\mu_{D(t)}$, which is commonly used in reliability engineering [10]. Since parts are reliable and the number of parts in use is large, we approximate the Poisson distribution with a normal distribution with mean $\mu_{D(t)}$ and variance $\sigma_{D(t)}^{2}$. Note that the variance value equals the mean value for a Poisson distribution.

However, this normal distribution requires some modification since part demand can not take on a negative value. The modified normal distribution is given as follows:

$$
\begin{aligned}
& \operatorname{Pr}[D(t) \leq \tau]=F_{D(t)}(\tau) \\
& =\left\{\begin{array}{cc}
1-\int_{\tau}^{\infty} \frac{1}{\sqrt{2 \pi} \sigma_{D(t)}} e^{-\frac{1}{2}\left(\frac{y-\mu_{D(t)}}{\sigma_{D(t)}}\right)^{2}} & \tau \geq 0 \\
0 & \tau<0
\end{array}\right.
\end{aligned}
$$

This distribution takes on a positive discrete probability that $D(t)=0$, i.e., that no part fails in " $t$ " point. Since the Poisson distribution cannot take on a negative number, this modified normal distribution better approximates the Poisson distribution.

There are three assumptions for developing economic models for the Lastbuy problem. First, a product (assembly) consists of several (components) parts and the probability that multiple parts in a product fail in the same t point is negligible. Second, any part shortage is not recovered in the later period (i.e., no backlogging is allowed). Third, the Lastbuy decision is made at the beginning of each period and the order is supplied within the given period. This allows us to eliminate a lead time factor. It is told by the field managers that these assumptions are close to real situations at S Electronics, where relatively high quality products in the market are supported through an efficient supply chain management system.

\subsection{The Simple Economic Model}

The total cost of the economic model is divided into three parts: Ordering cost, inventory cost, and shortage cost. The total cost $T C(x)$ is computed by the following formula:

$$
\begin{aligned}
& T C(x)=c l \cdot x \\
& +\left[c v \cdot \sum_{t=1}^{U T L} \int_{0}^{h(t)}(h(t)-D(t)) f(D(t)) \mathrm{d} D\right] \\
& +\left[c s \cdot \sum_{t=1}^{U T L} \int_{h(t)}^{\infty}(D(t)-h(t)) f(D(t)) \mathrm{d} D\right]
\end{aligned}
$$

where

$$
h(t+1)=\left\{\begin{aligned}
h(t)+x \text { for } t & =0 \\
\max \{h(t)-D(t), 0\} & \text { for } t>0
\end{aligned}\right.
$$

We call this formula as the simple order economic model. Note that there is no setup cost in this model. This is because the production line is still up running at this point of Lastbuy order. A nonnegative $h(t)$ is used in calculating the expected shortage cost due to the assumption of no backlogging policy.

\begin{tabular}{|c|c|c|}
\hline Variables & Descriptions & Notations \\
\hline Lastbuy quantity & $L T B$ order quantity of a part under consideration & $X$ \\
\hline Re-order point & The period when the re-order is issued. & $z$ \\
\hline Term of guarantee & Mandatory supply period of the part specified by law (or private law) & $U T L$ \\
\hline Demand in " $t$ " point & Demand for the part in time " $t$ " point & $D(t)$ \\
\hline Inventory quantity in " $t$ " point & $\begin{array}{l}\text { Inventory quantity of the part in " } t \text { " point. }(h(0) \text { is the inventory } \\
\text { on hand at the beginning before Lastbuy order.) }\end{array}$ & $h(t)$ \\
\hline Shortage quantity in " $t$ " point & Expected number of the part of shortage in time " $t$ " point & $\int_{h(t)}(D(t)-h(t)) f(D(t)) \mathrm{d} D$ \\
\hline
\end{tabular}

\subsection{The Re-Order Economic Model}

There are also occasions when the company is allowed to place one additional order (i.e., one time re-order). The company desires to know the amount of savings that

Table 2. Definitions of the economic model terminologies. 
could be gained with this one-time reorder or the penalty cost for which the company is willing to pay with this re-order. We denote $f c$ as the setup cost required to restart the discontinued production, and $\mathrm{cr}$ as the cost of one unit of the re-order, differing from $\mathrm{cl}$, the cost of one unit of the Lastbuy order. $c r$ tends to be larger than $c l$ due to extra material handling and higher part costs with one-time small size production from the discontinued line. The re-order timing $z$ also becomes a decision variable. For this variant of the problem, we present the re-order economic model.

The total cost of this re-order model is divided into two parts. The first part is the cost that occurs between the Lastbuy and re-order points. The second part is the cost that occurs between the re-order point and the guarantee of supply period. Thus, the total cost $T C_{r}(x, y, z)$ of the re-order model is given as follows.

$$
\begin{aligned}
& T C_{r}(x, y, z)=c l \cdot x \\
& +\left[c v \cdot \sum_{t=1}^{z-1} \int_{0}^{h(t)}(h(t)-D(t)) f(D(t)) \mathrm{d} D\right] \\
& +\left[c s \cdot \sum_{t=1}^{z-1} \int_{h(t)}^{\infty}(D(t)-h(t)) f(D(t)) \mathrm{d} D\right] \\
& +[f c+c r \cdot y] \\
& +\left[c v \cdot \sum_{t=z}^{U T L} \int_{0}^{h(t)}(h(t)-D(t)) f(D(t)) \mathrm{d} D\right] \\
& +\left[c s \cdot \sum_{t=z}^{U T L} \int_{h(t)}^{\infty}(D(t)-h(t)) f(D(t)) \mathrm{d} D\right]
\end{aligned}
$$

where $z$ is the point when the re-order is issued, (i.e., the beginning of period $z \geq 2$ ) and $y$ is the re-order quantity. Thus the inventory level $h(t)$ is given as follows:

$$
h(t+1)=\left\{\begin{aligned}
& h(0)+x \text { for } t=0 \\
& \max \{h(t)-D(t), 0\} \text { for } t<z \\
& \max \{h(t)-D(t)+y, 0\} \text { for } t=z \\
& \max \{h(t)-D(t), 0\} \text { for } t>z
\end{aligned}\right.
$$

Note that this model has three decision variables: Lastbuy $x$, re-order quantity $y$, and re-order timing $z$. In the following section, we present a solution method that determines these variables at the minimal total cost.

\section{Solution Methods for Optimal Lastbuy Quantity Determination}

With complex nature of the total cost functions $T C$ and $T C_{r}$, it is difficult to analytically derive the optimal solutions. The solution methods for the simple and re-order economic models hinge on the following empirical observation. The total cost functions $T C$ and $T C_{r}$ well behave, taking a form of convex functions with respect to the decision variables and making a nice trade-off among those holding, shortage, and setup cost factors. This observation is supported by experimental results with numerous test problems form the company, as will be discussed in Sections 5 and 6. This leads to the following solution methods.

\subsection{Solution Method for the Simple Economic Model}

We apply a bisection search method [11] (Figure 2) to find the minimal-cost $L T B$ quantity. This method consists of 3 steps.

Step 1. Set $a, b$, and $m$ such that $a<$ optimal LTB quantity $<b$ and $m$ is the center point between $a$ and $b$.



Figure 2. Bisection search method for the simple order model. 
Step 2. If $T C(m)>T C(m+1)$, then reset $a$ to the value of $m$. Otherwise, reset $b$ to the value of $m$. Recalculate center point $m$ between a and $\mathrm{b}$.

Step 3. Repeat step 2 until $|a-b|=1$. Then min $\{T C(a), T C(b)\}$ represents the minimum value and the corresponding quantity is the optimal LTB quantity.

\subsection{Solution Method for the Re-Order Economic Model}

For the optimal method for the re-order model, we modify the basic Hooke-Jeeves pattern search method [12] and give the following procedure.

Step 1. Define an initial point. Set maximum $L T B$ quantity $x$ and maximum re-order quantity $y$. Define the initial point $(x, y, z)$ as $x=$ half of maximum $x, y=$ half of maximum $y$, and $z=$ half of $U T L$. Compute $T C_{r}(x, y, z)$

Step 2. Define the cube of $3 \times 3 \times 3$ as shown in Figure 3 , where the center of the cube i.e., the center point is current $(x, y, z)$. Compute total cost $T C_{r}$ at each of the 26 points of the cube surrounding the center point. If the center point $T C_{r}(x, y, z)$ is smaller than the minimum of those $26 T C_{r}$ values, then the center point is the optimal re-order cost and current $(x, y, z)$ becomes the final solution. Terminate the solution procedure. Otherwise, go to Step 3.
Step 3. Define a new center point $(x, y, z)$ as the point giving the smallest $T C_{r}$ among those 26 values, and repeat Step 2.

Figure 4 is a flow chart showing more detail steps of the above solution procedure. In the flow chart, "mincost" is the variable representing the incumbent solution cost. The comparison operator of two values "==" means an equivalence.

In a theoretical sense, the unimodality property of the cost function is required for global optimality. Likewise, the convexity condition must be satisfied for the methods to reach at the globally optimal solutions. Therefore, the solution methods aforementioned are to be considered as local optimal procedures, but they obtained the global optimum for each of the 16 test problems used in Section 6 . The optimality of the final results has been verified via a series of complete enumeration.

\section{A Numerical Example}

In this example, we set UTL to 1 year and demands are accumulated on a monthly basis. The unit price of a part $c l$ is $\$ 125$. The interest rate per year is $6 \%$ (i.e., monthly rate becomes $0.5 \%$ ). The inventory cost of a part is $\$ 30$ per $1 \mathrm{~m}^{3}$ per month. The size of one part is $0.01 \mathrm{~m}^{3}$. The price of product that uses this part is $\$ 1500$. The



Figure 3. Cube of the pattern search method for the re-order economic model. 


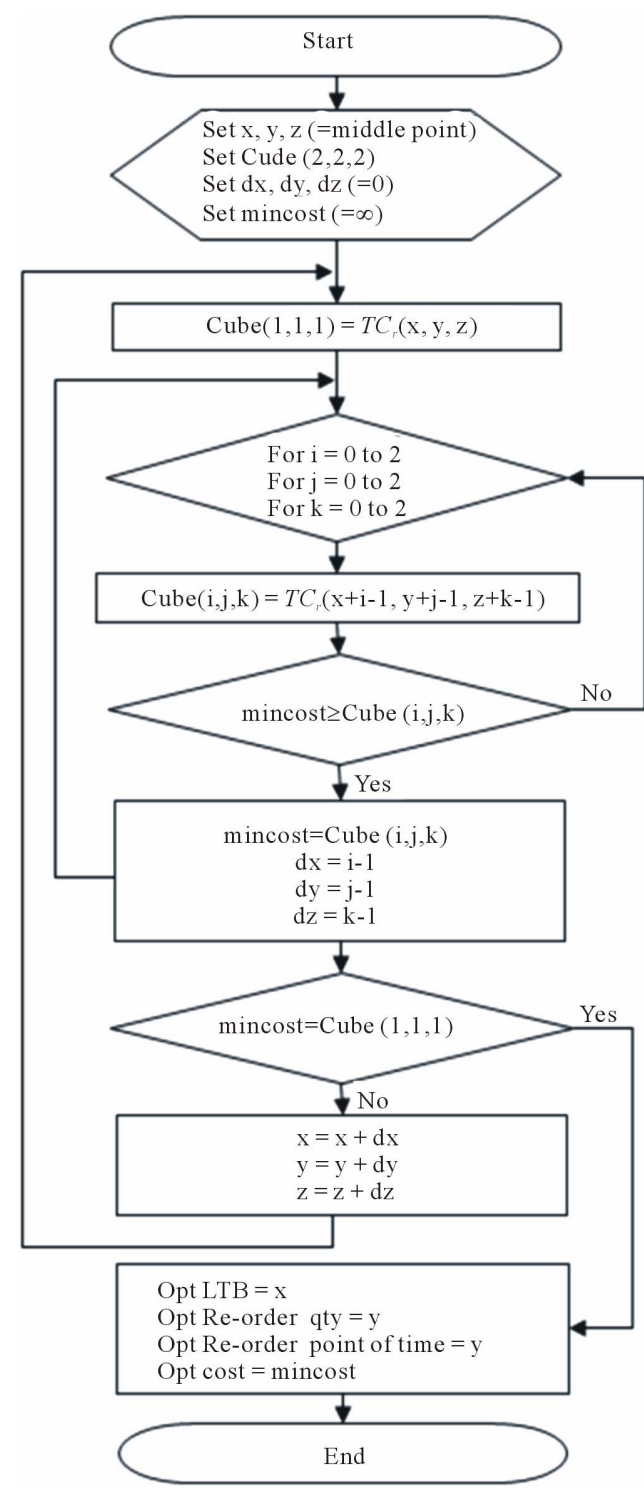

Figure 4. Flow chart of the pattern search method for the re-order economic model.

depreciation is $25 \%$ according to the company's consumerprotection law. Therefore we have $c v=0.005 \times$ $125+0.01 \times 30=\$ 0.93$ and $c s=0.25 \times 1500=\$ 375$. The mean demand quantity for $D(t)$ is shown in Table $\mathbf{3}$, which is obtained through exponential curve $100 e^{-0.4 t}$, one of S Electronics' forecasting curves. And the current inventory level at the beginning is set to 52 units. All of the cost factors are exact field data, although the demand and order quantity are reduced to a smaller number for illustration.

\subsection{Simple Economic Model Example}

In this section, we demonstrate an example to find the optimal $L T B$ Quantity of the simple economic model. We first set $a=0$ which should be smaller than the optimal quantity. Then we set $b=400$ which is about twice larger than the total demand value of 202 from Table 3, which is sufficiently larger than the opimal quantity. We set $\mathrm{m}=$ 200 , which is the center point of a and b. Since $T C(200)=$ $\$ 25,918<T C(201)=\$ 26,054$, we reset $b=200$. We repeat this step until the difference between $a$ and $b$ is decreased to 1. This is graphically displayed in Figure 5. The numbers (1 to 8) appearing on the figure correspond to the order of $T C$ computations. As shown in Figure 5, the final optimal $L T B$ quantity is 151 and its economic cost is $\$ 19,278$.

\subsection{Re-Order Economic Model Example}

In this example, we assume no penalty costs for reordering. The re-order fixed cost $f c$ is set to zero and the unit purchasing cost of the part does not increase, i.e., $\mathrm{cr}=\mathrm{cl}$. With these cost parameter values, the cost saving of the re-order model is equivalent to the maximum penalty allowable for the re-order policy. This allows us to demonstrate the true performance of the re-order model regardless of the penalty costs variations. The impact of re-order penalty is later delineated.

For the re-order economic model, we use a possible range of $L T B$ quantity $x$ and re-order quantity $y$ as shown in Table 4.

The center of the $3 \times 3 \times 3$ cube is $(x, y, z)$. The initial value of $(x, y, z)$ is $(60,60,6)$ which is determined by the center point of the maximum and the minimum. We compute $T C_{r}(60,60,6)=\$ 40,150$. Then we computer

Table 3. Mean demands for 12 periods.

\begin{tabular}{llllllllllllll}
\hline $\mathbf{T}$ & $\mathbf{1}$ & $\mathbf{2}$ & $\mathbf{3}$ & $\mathbf{4}$ & $\mathbf{5}$ & $\mathbf{6}$ & $\mathbf{7}$ & $\mathbf{8}$ & $\mathbf{9}$ & $\mathbf{1 0}$ & $\mathbf{1 1}$ & $\mathbf{1 2}$ & Total \\
\hline$\mu_{D(t)}$ & 67 & 45 & 30 & 20 & 14 & 9 & 6 & 4 & 3 & 2 & 1 & 1 & 202 \\
\hline
\end{tabular}

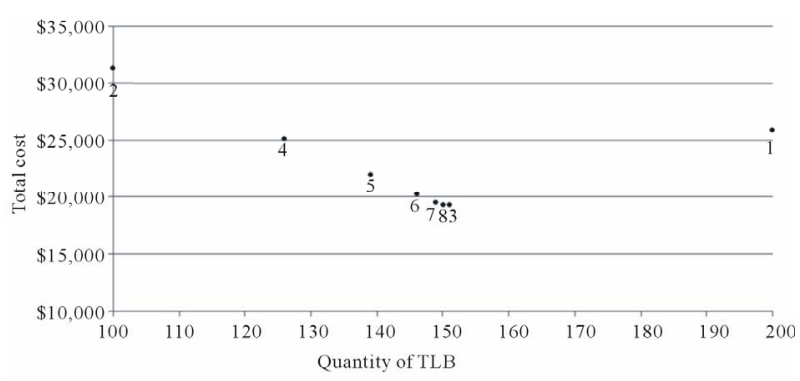

Figure 5. An example of the simple order model.

Table 4. Ranges of LTB qty and re-order qty.

\begin{tabular}{ccc}
\hline & Maximum & Minimum \\
\hline LTB qty & 100 & 20 \\
Re-order qty & 100 & 20 \\
\hline
\end{tabular}


the other 26 total costs in the cube: $T C_{r}(59,59,5)$, $T C_{r}(59,59,6), T C_{r}(59,59,7), T C_{r}(59,60,5), T C_{r}(59,60$, 6), $T C_{r}(59,60,7), T C_{r}(59,61,5), T C_{r}(59,61,6), T C_{r}(59$, 61, 7), $T C_{r}(60,59,5), T C_{r}(60,59,6), T C_{r}(60,59,7)$, $T C_{r}(60,60,5), T C_{r}(60,60,7), T C_{r}(60,61,5), T C_{r}(60,61$, 6), $T C_{r}(60,61,7), T C_{r}(61,59,5), T C_{r}(61,59,6), T C_{r}(61$, $59,7), T C_{r}(61,60,5), T C_{r}(61,60,6), T C_{r}(61,60,7)$, $T C_{r}(61,61,5), T C_{r}(61,61,6), T C_{r}(61,61,7)$.

$T C_{r}(61,59,5)=\$ 34,312$ is the smallest cost among these 26 costs. Since $T C_{r}(60,60,6)>T C_{r}(61,59,5)$, the cube moves in the direction of $(+1,-1,-1)$. We have a new $(x, y, z)$, which is $(61,59,5)$. We repeat this process until $T C_{r}(x, y, z)$ is smaller than all the 26 costs in the cube. In this example, the cube moves 17 times. This is graphically displayed in Figure 6. The optimal solution found is $(x, y, z)=(77,74,3)$ with total cost $\$ 19,145$. According to this solution, an order of 77 units is made at the beginning of period 1 and a re-order of 74 units is made at the beginning of period 3 .

The cost saving of this re-order model over the simple model is $\$ 133$ (i.e., 19,278 - 19,145 = 133), which can be interpreted as the maximum penalty cost allowable for the re-order policy. With the assumption of no part cost increase, the fixed cost is allowed as large as \$133. Or the penalty may be imbedded in the increased part purchase price for the re-order parts. Figure 7 shows the cost impact of re-oder decisions when the part price increases. As the re-order part price increases, the optimal re-order quantity decreases toward zero.

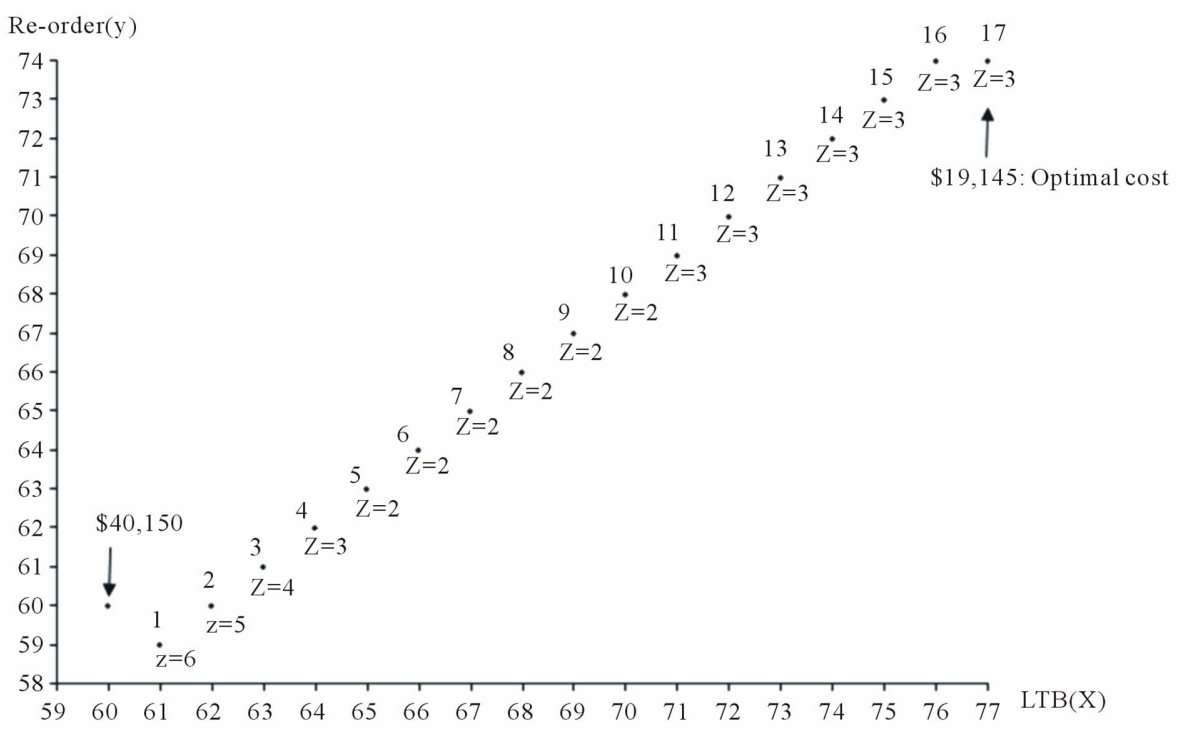

Figure 6. A numerical example of the re-order economic model.



Figure 7. The cost impact of price increments of the re-order part. 


\section{The Effects of the Economic Models}

We tested the proposed economic models by a set of computational studies using the real company data sets. The outcomes of the proposed methods were compared with those of the current practice by the company, which is to determine the Lastbuy quantity by summing the forecasted demands minus the initial inventory level on hand with no re-order.

For the validation purpose, we tested 16 parts of 8 different products manufactured by the company using its past records. We applied our proposed methods and the company practice to these 16 parts and Table 5 presents a summary of the comparison between the two outcomes. Columns A and B of Table 5 represent the relative Lastbuy quantity difference and the relative total cost difference for the simple model, respectively. Co- lumns $\mathrm{C}$ and $\mathrm{D}$ are the corresponding values for the re-order model. Column E shows the maximum ratio of part price increment after re-order. This can be served as an indication of the economic (or penalty) impact of the re-order model.

The total cost saving of the proposed method with the simple economic model is $0.57 \%$ on the average with

Table 5. A performance study of the proposed economic models. A: $\frac{\text { company Lastbuy qty - simple economic model qty }}{\text { company Lastbuy qty }} \times 100$
B: $\frac{\text { company Lastbuy cost }- \text { simple economic model cost }}{\text { company Lastbuy cost }} \times 100$
C: $\frac{\text { company Lastbuy qty - reorder economic model qty }}{\text { company Lastbuy qty }} \times 100$
D: $\frac{\text { company Lastbuy cost }- \text { reorder economic model cost }}{\text { company Lastbuy cost }} \times 100$
E: $\frac{\text { company Lastbuy cost }- \text { reorder economic model cost }}{\text { re }- \text { order } \text { qty } \times \text { price of part }} \times 100$

\begin{tabular}{|c|c|c|c|c|c|c|}
\hline \multirow[b]{2}{*}{ No. } & \multirow[b]{2}{*}{ Part description } & \multicolumn{2}{|c|}{ Simple economic model } & \multicolumn{3}{|c|}{ Re-order economic model } \\
\hline & & A & B & $\mathrm{C}$ & $\mathrm{D}$ & E \\
\hline 1 & HHP WINDO-009 & $-0.08 \%$ & $2.34 \%$ & $-0.09 \%$ & $6.90 \%$ & $30.79 \%$ \\
\hline 2 & HHP CAMERA-001 & $-0.02 \%$ & $0.21 \%$ & $-0.02 \%$ & $0.70 \%$ & $12.07 \%$ \\
\hline 3 & HHP CAMERA-031 & $-0.27 \%$ & $0.27 \%$ & $-0.27 \%$ & $1.21 \%$ & $12.02 \%$ \\
\hline 4 & HHP UPPER-017 & $-0.12 \%$ & $0.49 \%$ & $-0.11 \%$ & $2.40 \%$ & $9.26 \%$ \\
\hline 5 & AUDIO DECK-001 & $-0.24 \%$ & $0.06 \%$ & $-0.24 \%$ & $2.63 \%$ & $10.27 \%$ \\
\hline 6 & AUDIO DECK-018 & $-0.72 \%$ & $0.40 \%$ & $-0.72 \%$ & $9.12 \%$ & $33.34 \%$ \\
\hline 7 & WASHINGMACHINE PBA-004 & $-0.58 \%$ & $2.55 \%$ & $-0.67 \%$ & $9.54 \%$ & $35.25 \%$ \\
\hline 8 & WASHINGMACHINE PBA-014 & $-0.32 \%$ & $0.94 \%$ & $-0.39 \%$ & $5.88 \%$ & $106.97 \%$ \\
\hline 9 & DVD PBA-003 & $-0.36 \%$ & $0.56 \%$ & $-0.36 \%$ & $1.59 \%$ & $4.74 \%$ \\
\hline 10 & DVD DECK-007 & $-0.93 \%$ & $0.61 \%$ & $-0.93 \%$ & $2.19 \%$ & $3.23 \%$ \\
\hline 11 & MP3PLAYER PBA-014 & $-0.01 \%$ & $0.00 \%$ & $-0.01 \%$ & $1.39 \%$ & $5.62 \%$ \\
\hline 12 & MP3PLAYER PBA-030 & $-0.09 \%$ & $0.00 \%$ & $0.00 \%$ & $0.33 \%$ & $1.49 \%$ \\
\hline 13 & NOTE PC BOARD-007 & $-0.26 \%$ & $0.09 \%$ & $-0.26 \%$ & $2.40 \%$ & $9.72 \%$ \\
\hline 14 & NOTE PC BOARD-010 & $-0.07 \%$ & $0.01 \%$ & $-0.13 \%$ & $3.42 \%$ & $13.36 \%$ \\
\hline 15 & LCD MONITER MAIN-058 & $-0.66 \%$ & $0.50 \%$ & $-0.81 \%$ & $4.80 \%$ & $15.79 \%$ \\
\hline \multirow[t]{2}{*}{16} & PDP TV MODULE-001 & $-1.27 \%$ & $0.07 \%$ & $-1.27 \%$ & $2.84 \%$ & $7.02 \%$ \\
\hline & Average & $-0.38 \%$ & $0.57 \%$ & $-0.39 \%$ & $3.58 \%$ & $19.43 \%$ \\
\hline
\end{tabular}




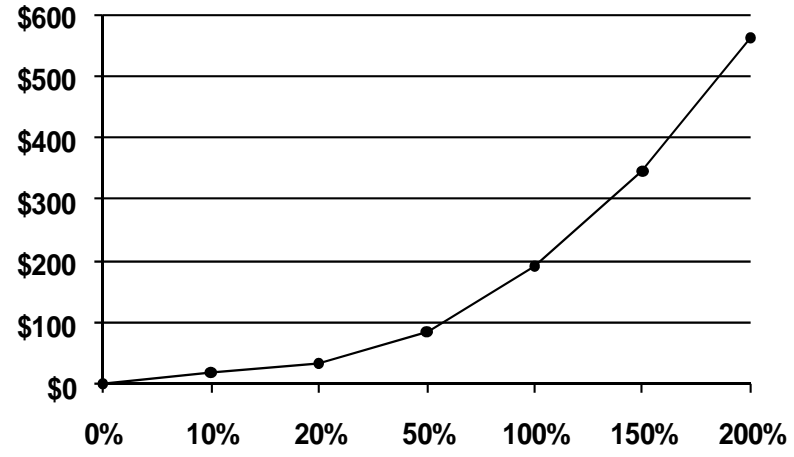

Figure 8. Cost saving as the rate of standard deviation increases.

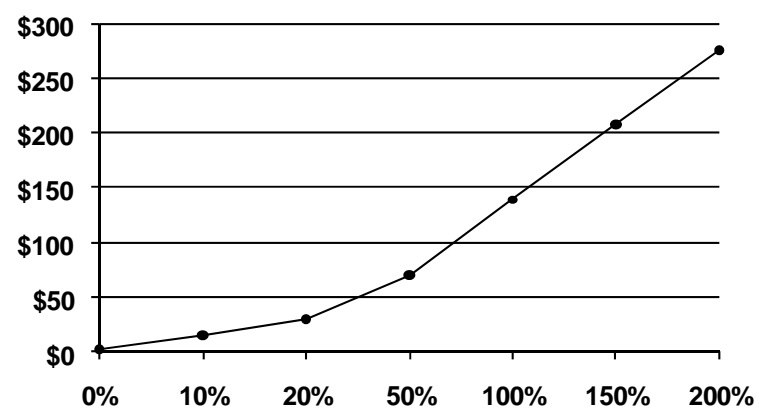

Figure 9. Cost saving cost as the rate of shortage cost increases.

$\max 2.55 \%$ (see column B), whereas that of the re-order model reaches average $3.58 \%$ with $\max 9.54 \%$ (see column D). It is also observed from column $\mathrm{E}$ that the re-order model solution may allow a penalty of average $19.43 \%$ with max $106.97 \%$ in the part price increase when compared to the simple model solution. This shows a great potential saving that the re-order policy could bring for the service part management.

In order to further investigate the effectiveness of the proposed models and solution methods, we conducted a sensitivity study on two key input parameters: standard deviation of the demand and shortage cost factor. Figures 8 and 9 depict the results from the numerical example of the simple economic model presented in Section 5. They show that the proposed method brings more significant cost savings as the standard deviation and shortage cost increase. The similar results are observed for other parts tested. This means that the effectiveness increases as demand uncertainty and customer expectation toward products increase. As demand stand deviation increases, the expected number of shortage increases, causing the current company practice to experience higher shortage costs.

\section{Conclusion}

In this paper, we presented the economic order quantity models and solution methods to determine the final purchase quantity necessary to support service parts for $S$ Electronics, one of the largest electronics company in the world. Our experimental results with the 16 company data sets show that the proposed methods save the cost over the company practice by average $0.57 \%$ and $3.58 \%$ $(\max 2.55 \%$ and $9.54 \%$ ) for the simple and re-order models, respectively. This translates into annual cost saving of about $\$ 0.6$ million dollars even in Korea alone. Considering S Electronics' world wide business scope and over 20,000 different parts types per year, the value of the proposed methods could lead to substantial saving. The sensitivity study also shows that the saving will increase furthermore as the demand uncertainty and customer expectation toward products increase. With these findings, the company recently adopted the proposed methods for real usage in its operation.

\section{REFERENCES}

[1] L. Fortuin and H. Martin, "Control of Service Parts," International Journal of Operations \& Production Management, Vol. 19, No. 9, 1999, pp. 950-971. doi:10.1108/01443579910280287

[2] L. Fortuin, "The All-Time Requirement of Spare Parts for Service after Sales: Theoretical Analysis and Practical Results," International Journal of Operations \& Production Management, Vol. 1, No. 1, 1980, pp. 59-70. doi:10.1108/eb054660

[3] L. Fortuin, "Reduction of the All-Time Requirement for Spare Parts," International Journal of Operations \& Production Management, Vol. 2, No. 1, 1981, pp. 29-37. doi:10.1108/eb054673

[4] L. Fortuin, "Initial Supply and Re-Order Level of New Service Parts," European Journal of Operational Research, Vol. 15, No. 3, 1984, pp. 310-319. doi:10.1016/0377-2217(84)90098-5

[5] R. H. Teunter and L. Fortuin, "End-Of-Life Service," International Journal of Production Economics, Vol. 59, No. 1-3, 1999, pp. 487-497. doi:10.1016/S0925-5273(98)00112-1

[6] W. J. Kennedy, J. Patterson, J. Wayne and D. Lawrence, "An Overview of Recent Literature on Spare Parts Inventories," International Journal of Production Economics, Vol. 76, No. 2, 2002, pp. 201-215. doi:10.1016/S0925-5273(01)00174-8

[7] J. Huiskonen, "Maintenance Spare Parts Logistics: Special Characteristics and Strategic Choices," International Journal of Production Economics, Vol. 71, No. 1-3, 2001, pp. 25-133. doi:10.1016/S0925-5273(00)00112-2

[8] T. E. Vollmann, W. L. Berry and D. C. Whybark, "Manufacturing, Planning and Control Systems," 4th Edition, McGraw-Hill Companies Inc., New York, 1997.

[9] B. W. Kim and S. S. Park, "Optimal Pricing, EOL (End of Life) Warranty, and Spare Parts Manufacturing Strategy Amid Product Transition," European Journal of 
Operational Research, Vol. 188, No. 3, 2008, pp. 723745. doi:10.1016/j.ejor.2007.04.036

[10] P. D. T. O'Connor, "Practical Reliability Engineering," John Wiley \& Sons, New York, 1995.

[11] G. V. Reklaitis, A. Ravindran and K. M. Ragsdell, "Engineerng Optimization Methods and Applications," John
Wiley \& Sons, New York, 1983.

[12] R. Hooke and T. A. Jeeves, "Direct Search of Numerical and Statistical Problems," The Journal of the ACM, Vol. 8, No. 2, 1966, pp. 212-229. doi:10.1145/321062.321069 